Aksiologiya: Jurnal Pengabdian Kepada Masyarakat

Vol.5, No. 2, Mei 2021 Hal 147 - 153

ISSN 2528-4967 (print) dan ISSN 2548-219X (online)

\title{
Penerapan Sistem Informasi Kepegawaian Pada Amal Usaha Muhammadiyah Kota Magelang
}

\author{
Rifqi Muhammad ${ }^{1}$, Ahada Nurfauziya ${ }^{2}$, Rizki Hamdani ${ }^{3}$ \\ ${ }^{1,2,3}$ Fakultas Ekonomi Universitas Islam Indonesia \\ Email : rifqimuhammad@uii.ac.id¹, ahadanur@uii.ac.id²,rizki.hamdani@uii.ac.id²
}

\begin{abstract}
ABSTRAK
Sebagai organisasi kemasayarakatan (Ormas) yang besar di Indonesia, Muhammadiyah terus sadar akan pentingnya nilai-nilai pembaharuan (up to date) untuk mengembangkan organisasi yang memiliki amal usaha yang sangat banyak. Amal usaha tersebut melibatkan Sumber Daya Manusia (SDM) yang cukup banyak dengan kompleksitas pengelolaan yang tinggi. Oleh karena itu, program pengabdian ini memiki fokus untuk menyusun sistem informasi kepegawaian muncul di lingkungan Amal Usaha Muhammadiyah (AUM) Pimpinan Daerah Muhammadiyah (PDM) Kota Magelang, Jawa Tengah. Pengelolaan kepegawaian yang sebelumnya menggunakan sistem manual dengan jumlah SDM yang dikelola sebanyak 248 dengan status yang beragam. Metode kegiatan pengabdian ini dilakukan dengan beberapa tahap, yaitu dengan mengidentifikasi masalah yang ada, menganalisis situasi dengan cara observasi lapangan dan wawancara kepada pihakpihak yang terkait, menetapkan program yang relevan, membuat model sistem kepegawaian yang relevan, melakukan penilaian kelayakan model sistem kepegawaian, dan membuat aplikasi sistem kepegawaian terintegrasi. Penerapan sistem informasi kepegawaian ini memberikan pengaruh yang signifikan terhadap performance organisasi Muhammadiyah Kota Magelang dan meningkatkan produktivitas para SDM. Program pengabdian ini juga telah membangun manajemen organisasi yang lebih profesional dan akuntabel.
\end{abstract}

Kata Kunci: amal usaha Muhammadiyah; Kota Magelang; sistem informasi kepegawaian

\section{Application of Personnel Information Systems in Muhammadiyah Business Charities in Magelang City}

\begin{abstract}
As a large social organization (Ormas) in Indonesia, Muhammadiyah continues to be aware of the importance of up-to-date values to develop an organization that has a lot of charitable efforts. This charity business involves quite a lot of Human Resources (HR) with high management complexity. Therefore, this service program has a focus on developing a staffing information system to appear in the Muhammadiyah Business Charity (AUM) Regional Leadership of Muhammadiyah (PDM) in Magelang City, Central Java. Personnel management previously used a manual system with 248 human resources with varying status. The dedication method activity is carried out in several stages, namely by identifying existing problems, analyzing the situation by means of field observations and interviews with relevant parties, establishing relevant programs, making relevant staffing system models, conducting an appropriateness assessment of the staffing system model, and create an integrated staffing system application. The application of the staffing information system has a significant influence on the performance of the Muhammadiyah organization in the City of Magelang and increases the productivity of the human resources. This dedication program has also built organizational management which is more professional and accountable.
\end{abstract}

Keywords: amal usaha muhammadiyah; Magelang City; staffing information system 


\section{PENDAHULUAN}

Muhammadiyah

merupakan sebuah organisasi Islam yang besar di Indonesia (Muhammadiyah.or.id, n.d.). Nama organisasi ini diambil dari nama Nabi Muhammad SAW, sehingga Muhammadiyah juga dapat dikenal sebagai orang-orang yang menjadi pengikut Nabi Muhammad SAW (Liputan6.com, 2019). Dalam pembentukan-Muhammadiyah banyak merefleksikan kepada perintahperintah Allah dalam Al-Qur'an, diantaranya surat Ali Imran ayat 104 (Q.S. Ali Imran [3]: 104), yang artinya:

"Dan hendaklah ada di antara kamu segolongan umat yang menyeru kepada kebajikan, menyuruh kepada yang ma'ruf dan mencegah dari yang munkar; mereka itulah orang-orang yang beruntung".

Berdasarkan Q.S. Ali Imran [3]: 104 tersebut, nyatalah bahwa Muhammadiyah adalah satu organisasi yang bersifat sebagai gerakan yang mempunyai ciri-ciri tertentu, antara lain; (1) Muhammadiyah adalah sebagai subjek/pemimpin dan masyarakat adalah objek/yang dipimpin; (2) Lincah (dinamis), maju (progresif), selalu di muka dan militan; (3) Revolusioner; (4) Mempunyai pimpinan yang kuat, cakap, tegas, dan berwibawa; dan (5) Mempunyai organisasi yang susunannya lengkap dan selalu tepat/ up to date (Suara Muhammadiyah dan Majelis Pendidikan Kader PP Muhammadiyah, 2010: 29-30).
Dalam butir ke-6 Muqaddimah Anggaran Dasar Muhammadiyah dinyatakan, melancarkan amal-usaha dan perjuangan dengan ketertiban organisasi, yang mengandung makna pentingnya organisasi sebagai alat gerakan yang niscaya (antara news.com, 2010). Amal Usaha Muhammadiyah (AUM) adalah salah satuusahamediadakwahdankaderisasi persyarikatan Muhammadiyah dalam rangka pencapaian maksud dan tujuan dari organisasi persyarikatan Muhammadiyah (Ilham, Gani, \& Arrahman, 2019: 142).

Struktur organisasi Muhammadiyah berdiri mulai dari Pimpinan Pusat, Pimpinan Wilayah, Pimpinan Daerah, Pimpinan Cabang, sampai dengan Pimpinan Ranting sebagai unit terkecil dalam organisasi Muhammadiyah (Safitri dkk, 2020). Budaya organisasi Muhammadiyah dibedakan antara sumber daya manusia (SDM) sebagai pengurus Muhammadiyah dan SDM yang bekerja di dalam AUM. Pengurus Muhammadiyah mulai dari tingkat pusat sampai dengan ranting bekerja secara sukarela (voluntary) sedangkan pengelola AUM bekerja secara profesional dan mendapat pengahasilan baik gaji maupun hak keuangan lainnya.

Dilihat dari data AUM yang ada pada Muhammadiyah.or.id (2019), Muhammadiyah memiliki beberapa bidang AUM yang cukup maju perkembangannya antara lain pendidikan (sekolah dan perguruan tinggi), kesehatan (rumah sakit, poliklinik), ekonomi (toko, bank 
syariah, dan percetakan), dan sosial dakwah kemanusiaan (lembaga amil zakaf, infak dan sedekah). Penerapan sistem informasi ini difokuskan pada sistem kepegawaian yang berada di tingkat Pimpinan Daerah Muhammadiyah (PDM) Kota Magelang, Jawa Tengah.

Ada beberapa keunikan yang menjadikan program ini penting dilakukan: Pertama, PDM Kota Magelangmemilikisistempengelolaan AUM secara tersentral. Hal ini dilakukan karena Kota Magelang hanya memiliki 3 kecamatan dengan 10 AUM saja sehingga lebih efektif jika dikelola secara tersentral.

Kedua, kondisi AUM berbedabeda secara kemampuan keuangan sehingga masih diberlakukan subsidi silang antar AUM dengan pertimbangan kemashlahatan. Ketiga, pengelolaan SDM masih bersifat tradisional sehingga masih menimbulkan ketidakjelasan proses dan status masing-masing SDM yang bekerja di AUM.

Agar pengelolaan SDM dalam suatu organisasi lebih efektif, keberadaan system informasi merupakan hal yang sangat penting. Terlebih ketika jumlah SDM sudah sedemikian besar, pengelolaan secara manual menjadi tidak efektif. Sistem informasi manajemen yang terintegrasi akan dapat menyajikan informasi-informasi yang bermanfaat untuk meningkatan produktivitas serta perbaikan manajemen dalam suatu organisasi (Kristianti \& Achjari, 2017: 9).

Sistem ini menggunakan perangkat keras maupun lunak dengan sebuah database sebagai input, kemudian akan diolah untuk menghasilkan informasi yang dapat digunakan manajemen untuk membuat keputusan. Pengambilan keputusan akan lebih cepat dilakukan berdasarkan informasi yang diambil dari database yang telah diotomatisasi sehingga memudahkan untuk melakukan data retrieve dengan lebih valid dan memiliki keandalan tinggi.

Sistem informasi yang baik adalah yang dapat menghasilkan informasi berkualitas sebagai dasar pengambilan keputusan (Lasmaya, 2016: 30). Secara umum, sistem informasi SDM sering disebut dengan sistem kepegawaian (SIMPEG). Sistem informasi berfungsi untuk mengumpulkan, menyimpan, memelihara dan memvalidasi berbagai data tentang SDM, kegiatan personalia dan karakteristik satuan kerja (Handoko, 2000: 237). Sistem kepegawaian yang dikembangkan mampu mengelola data dengan jumlah yang banyak namun dapat menghasilkan informasi yang terkait SDM dengan lebih akurat, tepat waktu saat dibutuhkan, relevan (sesuai dengan yang dibutuhkan saat kondisi tertentu), dan lengkap atau informasi tidak sepotong-potong (McLeod \& Schell, 2004: 69).

Hal ini akan mengakibatkan para SDM semakin semangat dan disiplin dalam bekerja karena kinerjanya selalu tercatat dengan baik bersamaan dengan perbaikan kesejahteraan, sehingga kinerja organisasi akan semakin meningkat karena dengan 
kenaikan disiplin kerja SDM akan diikuti oleh peningkatan kinerjanya (Siregar \& Hamdani, 2018: 169). Kehandalan sistem informasi juga akan meningkatkan reputasi organisasi di mata masyarakat karena memiliki sistem informasi yang mampu memberikan fakta yang relevan bagi stakeholder yang berkaitan.

Masalahutamayangdihadapioleh Pimpinan Daerah Muhammadiyah (PDM) Kota Magelang adalah belum adanya sistem informasi kepegawaian yang terintegrasi dan terkomputerisasi secara online sehingga menghambat proses perencanaan pengembangan SDM di lingkungan AUM Kota Magelang. Padahal jumlah SDM yang dikelola sudah cukup banyak dengan jumlah AUM yang berbedabeda jenjangnya mulai dari SD/MI, SMP, SMA/SMK dengan variasi jabatan struktural maupun fungsional yang tentunya akan mempengaruhi kesejahteraan yang diterima masingmasing SDM di AUM-AUM tersebut.

Oleh karena itu, kegiatan pengabdian ini akan dilakukan dengan tujuan untuk merumuskan konsep pengelolaan kepegawaian di lingkungan AUM Kota Magelang, menyusun desain sistem informasi kepegawaian serta fitur-fitur yang diperlukan, membangun software aplikasi untuk administrasi kepegawaian di lingkungan AUM Kota Magelang, dan menyusun dokumentasi sistem sebagai panduan untuk implementasi dalam bentuk modul. Pembuatan aplikasi sistem kepegawaian AUM menggunakan pendekatan yang mampu mendeteksi aktivitas yang dilakukan masingmasing SDM serta kinerjanya sesuai peraturan yang berlaku di lingkungan PDM Kota Magelang.

\section{METODE PENELITIAN}

Pengabdian ini dilaksanakan di lingkungan Amal Usaha Muhammadiyah Kota Magelang, Jawa Tengah. Metode kegiatan dilakukan dengan beberapa tahap, antara lain:

1. Mengidentifikasi masalah yang terdapat dalam lingkungan AUM PDM Kota Magelang.

2. Melakukan analisis situasi dengan cara observasi lapangan dan wawancara kepada pihak-pihak yang terkait.

3. Melakukan penilaian atas hasil analisis dan menetapkan program yang relevan.

4. Melakukan pengembangan model sistem kepegawaian yang relevan.

5. Melakukan penilaian kelayakan model sistem kepegawaian.

6. Membuat prototype aplikasi sistem kepegawaian terintegrasi.

\section{HASIL DAN PEMBAHASAN}

Dari hasil observasi, PDM Kota Magelang mengelola SDM sekitar 248 orang dengan status yang beragam. Data tersebut dapat dilihat pada Tabel 1. 
Tabel 1. Rincian SDM di Lingkungan AUM Kota Magelang

\begin{tabular}{|c|c|c|c|c|c|c|c|c|}
\hline AUM & U & $\frac{1}{2}$ & Eூ & 5 & $\sum^{\infty}$ & 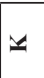 & 3 & 三 \\
\hline SD Muhammadiyah 1 & 8 & 2 & 40 & 10 & 0 & 0 & 0 & 60 \\
\hline SD Muhammadiyah 2 & 1 & 0 & 3 & 1 & 0 & 0 & 5 & 10 \\
\hline MI Muhammadiyah & 2 & 0 & 7 & 3 & 5 & 1 & 0 & 18 \\
\hline SMP Muhammadiyah & 7 & 0 & 14 & 11 & 0 & 0 & 0 & 32 \\
\hline SMA Muhammadiyah 1 & 9 & 4 & 16 & 7 & 6 & 0 & 0 & 42 \\
\hline SMA Muhammadiyah 2 & 6 & 1 & 10 & 2 & 0 & 0 & 0 & 19 \\
\hline SMK Muhammadiyah & 7 & 4 & 30 & 5 & 3 & 0 & 0 & 49 \\
\hline Toko Muhammadiyah & 0 & 0 & 0 & 0 & 0 & 10 & 0 & 10 \\
\hline LAZIS Muhammadiyah & 0 & 0 & 0 & 0 & 0 & 5 & 0 & 5 \\
\hline \multirow[t]{2}{*}{$\begin{array}{l}\text { Poliklinik } \\
\text { Muhammadiyah }\end{array}$} & 0 & 0 & 0 & 0 & 0 & 5 & 0 & 3 \\
\hline & 40 & 11 & 120 & 39 & 14 & 21 & 5 & 248 \\
\hline
\end{tabular}

Keterangan:

GTY: Guru Tetap Yayasan

KTY: Karyawan Tetap Yayasan

GTT: Guru Tidak Tetap

KTT: Karyawan Tidak Tetap

PNS: Pegawai Negeri Sipil

JLH: Jumlah

K: Kontrak

W: Wiyata

Dengan besarnya jumlah SDM yang dikelola dan komplesitas pengelolaan AUM dengan kondisi yang berbeda-beda, maka dari hasil observasi bahwa terdapat beberapa permasalahan yang sering muncul antara lain:

1. Kenaikan pangkat dan gaji sering tidak terdeteksi dan terlambat.

2. Status guru dan karyawan kontrak yang tidak jelas kontraknya sampai kapan dan bahkan ada yang belum mendapat surat kontrak perpanjangan.

3. Sistem reward dan punishment yang belum berjalan sehingga guru dan karyawan cenderung kurang disiplin dan kurang termotivasi.

4. Dokumentasi surat-surat keputusan terkait kepegawaian sering tercecer karena pergantian pengurusan PDM.

5. Hubungan kedinasan dengan instansi lainnya misalnya Dinas Pendidikan menimbulkan masalah karena data kondisi SDM yang tidak valid.

Dari hasil observasi, maka dirancang sistem kepegawaian yang sesuai dengan kebutuhan di lingkungan AUM Kota Magelang. Model sistem kepagawaian dapat dilihat pada Gambar 1.

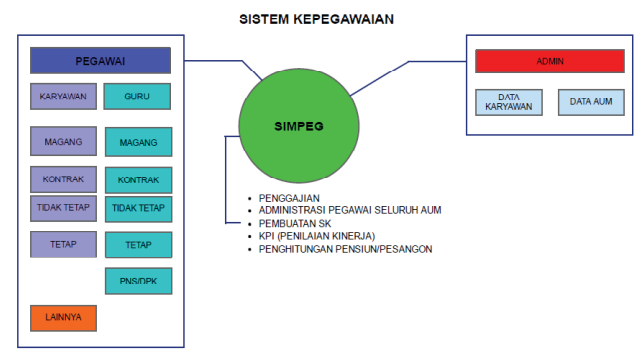

Gambar 1: Model Sistem

Kepegawaian AUM Kota Magelang

Kemudian dari hasil tindak lanjut, timpengabdianmenyewapengembang (developer) sistem aplikasi untuk membuat aplikasi sistem kepegawaian PDM Kota Magelang dengan pranala sementara: http://pdm.kuro.web.id/. Tampilan aplikasi sistem dapat dilihat pada Gambar 2 dan 3.

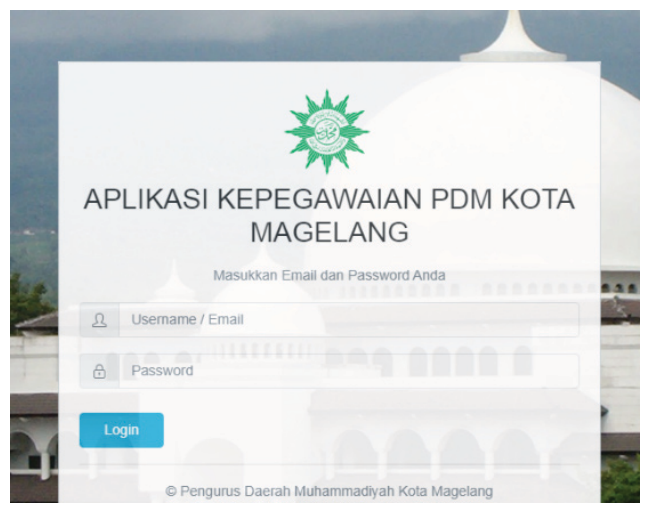

Gambar 2: Tampilan login 


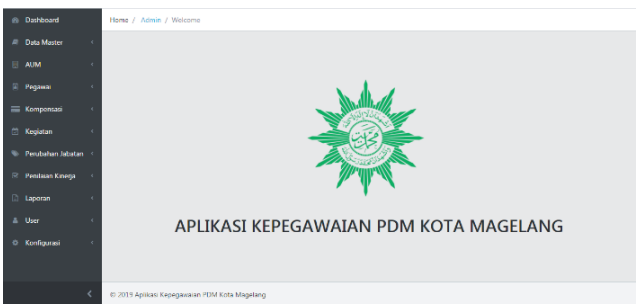

Gambar 3: Tampilan depan admin dan fitur sistem.

Dari hasil penerapan sistem kepegawaian ini, maka saat ini PDM Kota Magelang dapat dengan mudah memonitor para SDM yang ada. Beberapa permasalahan yang terjadi sebelumnya mulai teratasi, seperti pendeteksian performance dan gaji SDM, pendeteksian secara mudah dan cepat terkait status kepegawaian SDM, dan dokumentasi surat-surat keputusan terkait kepegawaian. Selain itu, dari sisi pegawai (SDM) juga dapat memanfaatkan sistem ini untuk kebutuhan administrasi sebagai laporan kinerja.

\section{SIMPULAN}

Penerapan sistem informasi kepegawaianinimemberikanpengaruh yang signifikan terhadap performance organisasi Muhammadiyah Kota Magelangdan produktivitas paraSDM. Program pengabdian yang dilakukan ini juga telah membangun manajemen organisasi yang lebih profesional dan akuntabel.Kegiatanpengabdianseperti ini sangat penting untuk dilaksanakan secara berkelanjutan dalam rangka mewujudkan manajemen organisasi yang sesuai dengan prinsip tata kelola yang baik (good governance).

Selain mengajar di kampus, para dosen Universitas Islam Indonesia yang memiliki kewajiban Catur Darma perguruan tinggi (Pengajaran, Penelitian, Pengabdian Masyarakat, dan Dakwah Islamiyah) harus senantiasa memberikan kontribusi yang membangun dan bermanfaat bagi masyarakat, baik dalam bentuk ide pemikiran dan juga tindakan praktis yang membantu masyarakat. Kegiatan ini merupakan perwujudan dari wujud pengabdian dan dakwah Islamiyah kepada masyarakat.

\section{UCAPAN TERIMA KASIH}

Penulis mengucapakan terima kasih kepada Direktorat Penelitian dan Pengabdian Masyarakat (DPPM) Universitas Islam Indonesia yang telah mendanai program pengabdian ini.

\section{DAFTAR PUSTAKA}

Al-Qur'an. Surat Ali Imran ayat 104. Al-Qur'an \& Terjemahannya (Al-Jumanatul Ali). CV Penerbit J-ART.

Antara News.com (2010). Muhammadiyah dan Gerakan Amar Ma'ruf Nahi Munkar. diakses dari https://www. antaranews.com/berita/209426/ muhammadiyah-dan-gerakanamar-maruf-nahi-munkar

Handoko, T. H. (2000). Manajemen Personalia dan Manajemen Sumber Daya Manusia. Yogyakarta: BPFE Universitas Gadjah Mada.

Ilham, I., Gani, A. A., \& Arrahman, R. (2019). Penerapan Baitul Arqam untuk Peningkatan Nilai Al Islam dan Kemuhammadiyah bagi Dosen Universitas Muhammadiyah Mataram. Aksiologiya: Jurnal Pengabdian Kepada Masyarakat, 3(2), 141. https://doi.org/10.30651/aks. 
v3i2.1839

Kristianti, C. E., \& Achjari, D. (2017). Penerapan sistem enterprise resource planning: Dampak terhadap kinerja keuangan perusahaan. Jurnal Akuntansi \& Auditing Indonesia, 21(1), 1-11. https://doi.org/10.20885/ jaai.vol21.iss 1.art1

Lasmaya, S. M. (2016). Pengaruh Sistem Informasi SDM Kompetensi Dan Disiplin Kerja Terhadap Kinerja Karyawan. Journal Ekonomi, Bisnis \& Entrepreneurship, 10(1), 2543.

Liputan6.com. (2019). Tujuan Organisasi Muhammadiyah, Terwujudnya Masyarakat Islam yang Sebenar-benarnya.

McLeod, J. R., \& Schell, G. P. (2004). Sistem Informasi Manajemen. Jakarta: PT. Indeks.

Muhammadiyah.or.id. (n.d.). Tentang Muhammadiyah. Diakses dari http://m.muhammadiyah.or.id/ $\mathrm{id} /$ content-44-cam-tentangmuhammadiyah.html

Muhammadiyah.or.id. Muhammadiyah.

Muhammadiyah.or.id. (2019). Data Amal Usaha Muhammadiyah.

Safitri, E. B., Octhavia, R., Febriyanti, V., Rifqianto, E. D., \& Rochmawati, F. (2020). Increased Human Resources by Muhammadiyah Payaman Branch Chairperson: Peningkatan Sumber Daya Manusia oleh Pimpinan Ranting Muhammadiyah Payaman. Proceeding of The ICECRS Vol 8 (2020): Educational and Psychological Conference in the 4.0 era.

Siregar, D. I., \& Hamdani, R. (2018). Disiplin Kerja dan Kinerja Karyawan: Bukti dari Perusahaan Gas Negara Wilayah Sumatera Utara. Future Jurnal Manajemen Dan Akuntansi,
5(2), 162-170.

Suara Muhammadiyah dan Majelis Pendidikan Kader PP Muhammadiyah. (2010). Manhaj Gerakan Muhammadiyah: Ideologi, Khittah, dan Langkah. (I. Nasri, H. Nashir, \& D. Sudjarwo, Eds.) (Cetakan Ke). Yogyakarta: Suara Muhammadiyah. 